\title{
Spatial distribution and determinants of childhood stunting among under-five children in Ethiopia: evidence from the 2019 Ethiopian demographic and health survey
}

Delelegn Emwodew ( $\nabla$ delelegn1244@gmail.com )

Dilla University

Binyam Tariku

Dilla University

Getanew Aschalew

Dilla University

Elias Seid

Jimma University

Samuel Hailegebreal

Arbaminch University

Abel Desalegn

Dilla University

Endris Seid Amede

Dilla University

\section{Research Article}

Keywords: Stunting, Spatial, Multilevel, Individual factors, Community factors, Under-five children, Ethiopia

Posted Date: August 4th, 2021

DOl: https://doi.org/10.21203/rs.3.rs-689775/v1

License: (9) This work is licensed under a Creative Commons Attribution 4.0 International License. Read Full License 


\section{Abstract}

Background: Childhood stunting is a major challenge to the growth and development of nations by affecting millions of children across the world. Although Ethiopia has made steady progress in reducing stunting, the prevalence of stunting is still one of the highest in the world. This study aims to investigate the spatial variation and factors associated with childhood stunting in Ethiopia.

Methods: This study is a secondary data analysis of the 2019 Ethiopian Mini Demographic and Health Survey (EMDHS). A total of 4,971 children aged 0-59 months were included in the analysis. The GetisOrd statistics tool has been used to identify areas with high and low hotspots of stunting. A multilevel logistic regression model was used to identify factors associated with stunting.

Results: The prevalence of stunting was found to be $36.86 \%$ in Ethiopian under-five children. Statistically significant hotspots of stunting were found in northern parts of Ethiopia. Both individual and communitylevel factors determined the odds childhood stunting among under-five children. Children in the age group between 24-35 months were more likely to be stunted than children whose age was less than one year [AOR = 3.74; $95 \% \mathrm{Cl}$ : (3.04-4.59)]. Children with mothers who had completed higher education had lower odds of being stunted compared to children whose mothers had no formal education $[\mathrm{AOR}=0.55 ; 95 \% \mathrm{Cl}$ : (0.38-0.82)]. Children from the poorest wealth quintile had higher odds of being stunted compared to children from the richest wealth quintiles [AOR $=2 ; 95 \% \mathrm{Cl}$ : (1.46-2.73)]. Children living in Tigray (AOR $=3.64 ; 95$ \% Cl: 2.17-6.11), Afar (AOR 2.02; 95 \% Cl 1.19-3.39), Amhara (AOR =2.29; 95 \% Cl: 1.37-3.86), Benishangul Gumz (AOR=1.87; 95\% $\mathrm{Cl}$ : 1.10-3.17) and Harari (AOR=1.95; 95\% $\mathrm{Cl}$ : 1.17-3.25) regions were more likely to be stunted compared to children living in Addis Ababa.

Conclusion: This study showed that both individual and community-level factors were significant predictors of childhood stunting. Improving maternal education, improving the economic status of households, improving age-specific child feeding practice, and providing additional resources to regions with high hotspots of childhood stunting are recommended.

\section{Introduction}

Stunting is defined as "an impaired growth and development of children due to inadequate nutrition, repeated infections, and inadequate psychosocial stimulation" [1]. Height for age Z-score is the growth score of years to use the indicator as a line for growth retardation and cumulative growth deficit in children. Children whose Z-score of growth at age below minus two standard deviations (-2 SD), which is the median of the reference population, are considered short for their age (stunted) [1]. Stunting affects the number of children around the world, and there are serious short-and long-term health consequences, including impaired cognitive function, poor educational performance, low adult wages, and poor reproductive outcomes $[2,3]$. Stunted children also have a higher risk of being overweight or obese later in life, putting them at risk of chronic disease in adulthood [4-6]. 
The magnitude and distribution of childhood stunting vary across different regions of the world. The global prevalence ranges from highest (35.2\%) in East and Central Africa to the lowest (2.6\%) in North America [7]. Although Ethiopia has made steady progress in reducing stunting (from 2005-2019 the prevalence of stunting has decreased from $51 \%$ to $37 \%$ ), the prevalence of stunting is still one of the highest in the world and continues to be a serious public health problem within the country [8].

According to several studies; factors such as sex, maternal education, father education, maternal occupation, household income, antenatal care service utilization, source of drinking water, type of latrine facility, and methods of feeding significant predictors of stunting in Ethiopia [9-14]. Although studies have investigated the spatial distribution of stunting in Ethiopia, they used old and out-dated data which could not exhibit the current situation in the country. To better understand the persisting challenges to reducing stunting in Ethiopia, we used the recent National Demographic and Health Survey (EMDHS 2019). In addition, most previous studies use a standard logistic regression model to identify independent predictors of stunting. Analyzing variables from different levels through the standard binary logistic regression model leads to biased results. Households in the same geographic cluster have common features such as seasonal changes, types of crops, and population density which can have a similar effect on the nutritional status of children in the cluster. The assumption of independence between individuals within the same cluster and equal variance between groups is violated in the case of grouped data. Therefore, multilevel analysis is the appropriate statistical analysis method for such a study. This study employed a multilevel logistic regression analysis which allows us to simultaneously study the influence of predictors of the group and individual level.

This study aimed to study the spatial variation of stunting and the factors associated with stunting in Ethiopia using spatial and multilevel analyses. The finding of this study would help the Ethiopian Government strategically intensify interventions to reduce under-nutrition-related mortality in the country.

\section{Methods}

\section{Study design and setting}

The study used data from the 2019 Ethiopian Mini-Demographic and Health Survey (EMDHS). The 2019 EMDHS is a population-based household survey conducted in Ethiopia from March 21 to June 28, 2019. Ethiopia is located in the North-Eastern part of Africa or known as the "Horn of Africa." It is bounded by the north and south Sudan on the west, Eritrea and Djibouti to the northeast, Somalia to the east and southeast, and Kenya to the south. Ethiopia lies between the $3^{\circ} \mathrm{N}$ and $15^{\circ} \mathrm{N}$ Latitude and $33^{\circ} \mathrm{E}$ and $48^{\circ}$ E Longitude.

\section{Sampling procedure}

EMDHS 2019 uses the two-step stratified cluster sampling method in which sample households have chosen within clusters EAs (Enumeration areas). At the first stage, a total of 305 EAs were selected (93 
live in urban areas and 212 in rural areas) with a probability proportional to the size of the EA and with independent selection in each sampling stratum. At the second stage of selection, a fixed number of 30 households in each cluster were selected, along with the probability of systematic selection of newly formed houses in the list. For our study, a total weighted sample of 4,971 children was used in the final analysis.

\section{Measurements}

The 2019 EMDHS collected data on the nutritional status of children by measuring the weight and height of children under age 5 . The length of children aged $<24$ months were measured lying down on the board (recumbent length), while children $\geq 24$ months were measured standing up. The height-for-age Z-score, an indicator of nutritional status, as compared with reference data from the WHO Child Growth Standards reference population, 2006. Children whose height-for-age Z-score is < -2 SD from the median of the WHO reference population are considered stunted (short for their age). Any additional information about data collection, sampling, and questionnaires used in the survey are described in detail in the 2019 EMDHS report [8].

\section{Study variables}

The outcome variable for this study was stunting, which is dichotomized as stunted (if height-for-age $Z$-score $<-2$ SD from the median of the reference population) and normal (if height-for-age Z-score >= $-2 \mathrm{SD}$ from the median of the reference population). Both individual and community-level factors were considered as the potential predictor variables. The individual-level factors included were child age, child sex, maternal education, wealth index, number of under-five children in the household, type of birth, and preceding birth interval. The four variables place of residence, region, type of latrine facility, and source of drinking water were considered as community-level factors.

\section{Data management and analysis}

Data cleaning was carried out to check for consistency. Data analysis was done using STATA version 14.2 and spatial analysis was done using ArcGIS software, version 10.8. Sample weights were done to adjust for non-proportional allocation of the sample to strata and regions during the survey process and to restore representativeness. Descriptive and summary statistics were conducted to describe the study population. A multi-level logistic regression analysis was carried out to account for the hierarchal nature of the DHS data.

\section{Spatial analysis}


ArcGIS 10.7 software was used for spatial analysis of the data. Spatial autocorrelation (Global Moran's I) statistics and Getis-Ord local cluster analysis were done to display the spatial distribution of childhood stunting in Ethiopia. The spatial Autocorrelation (Global Moran's I) is a tool used to verify whether childhood stunting is spatially clustered, dispersed or randomly distributed in Ethiopia. The tool calculates Moran's I Index value and both Z score \& p-value to evaluate the significance of the index. Moran's I index close to -1 indicates dispersing of childhood stunting whereas, close to 1 indicates clustering. Statistically significant Z-score and P-value $\leq 0.05$ lead to rejection of the null hypothesis showing the existence of clusters stunting[15]. Statistically non-significant Moran's I value (if $p$-value > 0.05 ) will indicate stunting is randomly distributed throughout the country [15].

The spatial heterogeneity of significant-high prevalence/low prevalence areas of stunting was computed for each cluster using the Getis-Ord G-statistic tools. The Local Getis-Ord G index helped to classify the autocorrelations into positive and negative correlations. If prevalence rates had similarly high values or low values, they were defined as positive autocorrelation hotspots (represented as High- High or Low-Low autocorrelation). If the attributes held opposing high and low values, they were considered to have negative autocorrelation (represent as High-Low or Low-High autocorrelation) [15]. To determine the significance of these statistics, Z-scores and P-values were used. A positive Z-score with a P-value of $<0.05$ indicates statistical clustering of hotspots of childhood stunting whereas a negative Z-score with a p-value of $<0.05$ indicates statistical clustering of children who are not stunted.

Kuldorff's Sat Scan version 9.4 software was used to identify the geographical locations of statistically significant clusters of stunting. Bernoulli's model was fitted to identify statistically significant locations of clusters. The Bernoulli model was selected because the structure of the data shows the binomial [0/1] distribution. The stunted child was considered as a case and labelled 1 whereas; normal child controlled and labelled 0 . The default $50 \%$ of the population was used as an upper limit for cluster size; because it allows the detection of both small and large clusters of stunting. Statistically significant clusters were identified by P-value and likelihood ratio tests. Multilevel analysis

Multivariable multilevel logistic regression was used to analyze factors associated with childhood stunting at two levels: individual and community (cluster) levels. Four models were fitted for this multilevel logistic regression analysis. The first model was an empty model without any explanatory variables to evaluate the extent of the cluster variation on stunting, the second model with individual-level variables, the third model with community-level variables, and the fourth model with both the individualand community-level variables. A P-value of $<0.05$ was used to define statistical significance. Adjusted Odds Ratios (AOR) with their corresponding $95 \%$ confidence intervals (Cls) was calculated to identify the independent predictors of stunting. We used the Bayesian Deviance Information Criterion (DIC) as a measure of the goodness of fit of the models. Intra-class correlation coefficient (ICC), proportional change in variance (PCV), and median odds ratio (MOR) were calculated to measure the variation between clusters.

\section{Results}




\section{Characteristics of participants}

A total of 4,971 children were included in this study. Almost half of these children were females $(49 \%$; $2441 / 4971)$. Over half $(53.60 \% ; 2665 / 2971)$ of mothers were not educated. The poorest wealth quintile comprises about $22.97 \%(1140 / 4971)$ of the total population. A total of $20.12 \%(1000 / 4971)$ of the children were infants less than a year and $74.88 \%$ (3722/4971) were from rural areas. Most of the children $(83.67 \%$; $4160 / 4971)$ had a preceding birth interval of 24 months and above.

The prevalence of childhood stunting was $37 \%(95 \% \mathrm{Cl}: 34.53,39.25)$. About $40.04 \%$ of stunted children were males, $45.45 \%$ of them were aged $24-35$ months, and $40.62 \%$ lived in rural areas. The proportion of stunted children were found higher among children in the Tigray region (49\%), having $<24$ months of birth interval (42.66\%), no education of mother (41.68\%), and poorest wealth index (42.63\%). Moreover, more than half $(57.41 \%)$ of children with multiple birth types were stunted. Table 1

\section{Spatial distribution of stunting in Ethiopia}

The study reveals the spatial distribution of childhood stunting in Ethiopia was non-random. The output from Global autocorrelation statistics shows spatial clustering of stunting with Moran's I index $0.37, \mathrm{Z}$ score of 8.2, and P-value $<0.01$. The positive $Z$ score and the minimum p-value indicate that there is less than $1 \%$ likelihood that the observed clustering was the result of random chance. The Getis-Ord hot spot analysis identifies hot spots (areas where high cases are surrounded by high cases) and cold spot areas (where low cases are surrounded by low cases). Hot spot clusters were observed in the Amhara region (East Gojam, North and South Gondar zones and South Wollo zone), and in the SNNP region (Sidama, Wolayta, Hadiya, and Gamo Gofa zones). Figure 1 shows the spatial distributions of stunting in Ethiopia.

\section{Sat scan analysis of stunting in Ethiopia}

From the output of Sat scan analysis, one big primary cluster containing 61 locations and 6 small nonsignificant clusters was identified. The primary cluster was located in the Amhara region (North and South Gondar zones and South Wollo zone), South Tigray zone, and in Afar regional state. The spatial window of the primary cluster was centered at $11.818783 \mathrm{~N}, 39.955788 \mathrm{E}$ with a $279.39 \mathrm{~km}$ radius, the relative risk of 1.50 , and the log-likelihood ratio of 42.97 at $P$-value $<0.001$. This means children living in this cluster $50 \%$ more likely stunted when compared with those living outside the cluster. The $p$-value is significant enough to conclude that this cluster was not the result of random chance. Figure 2 shows the output from Sat scan analysis of childhood stunting in Ethiopia.

\section{Multilevel analysis}

\section{The measure of variation (random effect) and model fitness}


As shown in Table 2, the null model (Model 1) revealed statistically significant variation in childhood stunting across communities (community variance $=0.436, \mathrm{P}<0.001$ ), in which $11.7 \%$ of the variation in the odds of childhood stunting is attributed to the community level factors (ICC=11.7\%).

After adjusting the model for individual-level factors (Model 2), the variation in the odds of childhood stunting remained statistically significant (community variance $=0.326, P<0.001$ ) across the communities, with $9.1 \%$ of the variance in the odds of childhood stunting could be attributed to the community-level factors

Model 3, which is adjusted for community-level factors, revealed a statistically significant variance of childhood stunting (community variance $=0.191, \mathrm{P}<0.001$ ) across the communities. In this model, the community-level factors explained $56 \%$ of the variability in the odds of childhood stunting (PCV $=56.2 \%$ ), and $5.5 \%$ of the variation among the clusters was attributed to community-level factors (ICC $=5.5 \%$ ).

The final model (model 4), which adjusted for both individual and community-level factors simultaneously, depicted statistically significant variability to the odds of a child being stunted (community variance $=0.166, \mathrm{P}<0.001$ ). In this model, about $5 \%$ of the variability among communities in the odds of a child being stunted was due to the community-level factors (ICC $=4.8 \%$ ) and about $70 \%$ of the variance in the odds of childhood stunting (PCV $=61.9 \%$ ) across communities was attributed to both individual and community-level factors.

Moreover, the MOR confirmed that childhood stunting was attributed to community-level factors. The MOR for stunting was 1.88 in the empty model; this indicated that there is variation between communities (clustering) since $M O R$ is greater than the reference $(M O R=1)$. The unexplained community variation in stunting decreased to a MOR of 1.47 when all factors were added to the null model (empty model). This shows that when all factors are considered, the effect of clustering is still statistically significant in the full model. Regarding model fitness, the final model (incorporate both individual and community level factors) was the best-fitted model for this data since it had the lowest deviance.

\section{Factors associated with childhood stunting}

The results of multilevel logistic regression models for individual and community-level factors are presented in Table 3. In the final model, where all individual and community level factors are included child sex, child age, birth interval, type of birth, mother educational status, wealth index, and region were factors significantly associated with childhood stunting.

\section{Individual-level factors}

Children aged 24-35 months old were 3.74 times (AOR $=3.74 ; 95 \% \mathrm{Cl}: 3.04-4.59)$ more likely to be stunted than children less than one-year-old. The odds of stunting were increased by $21 \%$ ( $A O R=1.21$; $95 \% \mathrm{Cl}: 1.06-1.37)$ in male children compared to females. Children with mothers who completed higher education were $45 \%(\mathrm{AOR}=0.55 ; 95 \% \mathrm{Cl}$ : 0.38-0.82) less likely to be stunted compared to those 
children whose mothers had no formal education. Children with multiple birth types were 2.46 times (AOR $=2.46 ; 95 \% \mathrm{Cl}: 1.62-3.74)$ more likely to be stunted than children with single birth types. The odds of stunting were $30 \%$ higher among children with a shorter (<24 months) birth interval compared to children with a longer birth interval ( $\geq 24$ months) ( $A O R=1.30 ; 95 \% \mathrm{Cl}: 1.11-1.53$ ). Children from the poorest wealth quintile were 2 times $(A O R=2.00 ; 95 \% \mathrm{Cl}: 1.46-2.73)$ more likely to be stunted than children from the richest wealth quintile.

\section{Community-level factors}

Children living in Tigray (AOR =3.64; 95 \% Cl: 2.17-6.11), Afar (AOR 2.02; 95 \% Cl 1.19-3.39), Amhara ( $A O R=2.29 ; 95 \% \mathrm{Cl}: 1.37-3.86)$, Benishangul Gumz (AOR=1.87; 95\% Cl: 1.10-3.17) and Harari $(A O R=1.95 ; 95 \% \mathrm{Cl}: 1.17-3.25)$ regions were more likely to be stunted compared to children living in Addis Ababa.

\section{Discussion}

This study determined the spatial distribution and predictors of child stunting in Ethiopia using the 2019 EMDHS data set. The prevalence of childhood stunting was $36.86 \%$, which indicated that childhood stunting remains a serious public health challenge in Ethiopia. The finding of this study showed that childhood stunting had significant spatial variation in Ethiopia. The output from global autocorrelation analysis shows significant clustering of childhood stunting in Ethiopia. This finding is in line with studies conducted in the same area using the previous version of the EDHS data set [16-18].

In this study, Getis-Ord spatial statistics showed the spatial variation of childhood stunting at the cluster level. Statistically significant hotspot areas of childhood stunting were observed particularly in the Amhara region (East Gojam, North and South Gondar, and South Wollo zones) and SNNP region (Sidama, Wolayta, Hadiya, and Gamo Gofa zones). This finding is in line with previous studies conducted on the 2011 and 2016 EDHS datasets $[17,18]$. This shows that even though the country is on-road towards reducing childhood stunting, significant change in reducing the burden of the problem has not been observed in the specified areas. The reason why these areas are more affected by child stunting may be due to geographic and climatic factors. These areas are known for their dryness and unsuitable for crop production. This consequently may create food shortage and occurrence of starvation in the society where children are more affected. Exploring spatial variation is important to identify aggregations of cases in order to target nutritional interventions [19]. The identified clusters might be the areas where childhood stunting prevention and control interventions should be given priority [20].

The Sat scan analysis was used to identify the actual geographical location of clusters and to test whether these clusters are statistically significant. The output from this analysis identified one big primary cluster that contains 61 enumeration areas. The primary cluster was located in the Amhara region (North and South Gondar zones and South Wollo zone), South Tigray zone, and in Afar regional state. This finding is similar to the hot spot analysis result except the hot spot identified in SNNP 
presented to be non-significant in Sat scan analysis. This finding is also in line with previous studies conducted in the same area $[17,18,21]$.

This study also identified both individual and community-level factors that have a significant association with childhood stunting. At the individual level factors such as sex and age of the child, birth interval, birth type, wealth index, and maternal education were found to be significantly associated with the odds of childhood stunting. Similarly, the region was an independent predictor of childhood stunting at the community level.

In this study, childhood stunting was found to be significantly associated with the age of the child; as the child's age increases the odds of being childhood stunted increases. Similar studies were reported in Bangladesh, Madagascar, and Malawi [22-24]. It could be due to the inappropriate and late introduction of low nutritional quality supplementary food [25] and a large portion of guardians in rural areas are ignoring to meet their children's optimal food requirements as the age of the child increases [26].

The current study also confirmed that male children were more likely to be stunted compared to females. This result is consistent with previous studies conducted in sub-Saharan Africa [27-29]. This might be due to preferences in feeding practices or other types of exposures [27]. Nutritional status can be defined as "biological instability" because boys are expected to grow at a faster rate compared to girls and their growth is probably more easily affected by a lack of healthy food or other diseases or exposure [30]. Gender differences in stunting were most common in areas where there was pressure such as on-going infection and exposure to toxins and air pollution [31].

Maternal education has been found to be negatively associated with childhood stunting. Many previous studies have found that maternal education has a positive effect on reducing childhood stunting [32-37]. These findings highlight the importance of girls' education as an alternative to combating the burden of childhood stunting and suppressing sensible eating habits in young children. The knowledge that mothers acquire from formal education can help them to develop important eating habits and hygiene that prevent childhood stunting. Another possible reason is that educated mothers have better healthseeking behaviors of childhood diseases compared to illiterate mothers which can help prevent stunting [38, 39].

Children from households in the poorest wealth quintile were also more likely to be stunted than children from the richest quintile, which is consistent with the findings of previous studies carried out in different developing countries [32, 40-42]. This could be due to the fact that increased income improves dietary diversity $[43,44]$, which in turn improves the adequacy of nutrient intake and nutritional status, and underscores the importance of linking income-generating activities with other nutritional interventions.

This study found that having a birth interval $\geq 24$ months decreased the odds of being stunted. This is consistent with other studies $[45,46]$. Short birth intervals can adversely affect the baby's nutrition by causing intrauterine developmental delays, and / or undermining the quality of child care [47]. Short birth 
intervals can adversely affect the baby's nutrition by causing intrauterine developmental delays, and /or undermining the quality of child care.

The present findings indicated that children from Amhara, Benishangul, and Tigray regions were more stunted compared to children from Addis Ababa which is similar to previous studies that compared regional variations in nutritional status $[17,18,48]$. This difference may be from the differential nutritional intake, the difference in the environment, socio-economic, and cultural differences [49].

\section{Strengths and limitations}

The representativeness of the data with a large sample size, as well as a nationally representative population-based study with a high response rate are strengths of this study that give high statistical power to infer the characteristics of the study population. Another important strength of this study is the use of multilevel logistic regression analysis, which was able to identify other factors beyond individuallevel factors that would not be identified by using standard logistic regression analysis.

The use of a combination of methods (spatial and regression statistics) was a strength that allowed validation of the identified hotspots areas due to the assumptions of the statistical methods. Despite the strength of our study, we have some limitations. Since the data was a cross-sectional type, it could not show causal inferences in relation to individual and community level factors with childhood stunting. Another limitation is the use of secondary data which has restricted the ability to include other variables such as behavioral factors and dietary aspects in relation to childhood stunting.

\section{Conclusion}

Statistically significant-high hotspots of stunting were found in northern parts of Ethiopia. Both individual and community-level factors determined childhood stunting. Being male, increased age of the child, short birth interval, multiple births, no formal education of mother, and being from a household in the lowest wealth quintile were the factors that increased the odds of stunting at the individual level. At a community level, children from the communities of Amhara, Tigray, and Benishangul suffer more from childhood stunting as compared to Addis Ababa's children. Thus, the improvement of the nutritional status of children requires multi-factorial interventions such as reducing poverty, ensuring adequate birth intervals, and educating mothers. The regions identified as having a high rate of childhood stunting should be prioritized for healthy food interventions.

\section{Declarations}

\section{Ethics approval and consent to participate}

Since the study was a secondary data analysis of publically available survey data from the DHS program, ethical approval and participant consent were not necessary for this particular study. We requested DHS 
Program and permission was granted to download and use the data for this study from http://www.dhsprogram.com. There are no names of individuals or household addresses in the data files. The geographic identifiers only go down to the regional level (where regions are typically very large geographical areas encompassing several states/provinces. In surveys that collect GIS coordinates in the field, the coordinates are only for the enumeration area (EA) as a whole, and not for individual households, and the measured coordinates are randomly displaced within a large geographic area so that specific enumeration areas cannot be identified.

\section{Consent for publication}

Not applicable.

\section{Availability of data and materials}

Data we used for this study are publicly available in the MEASURE DHS program and you can access it from www.measuredhs.com after explaining the objectives of the study. Then after receiving the authorization letter, the data is accessible and freely downloaded.

\section{Competing interest}

The authors declare that they have no competing interest.

\section{Funding}

The authors received no specific funding for this study.

\section{Authors' contributions}

$\mathrm{DE}, \mathrm{BT}$, and ES conceived the study, conducted the data analysis and interpretation.

$\mathrm{GA}, \mathrm{SH}, \mathrm{AD}$, and ESA assisted the data analysis and interpretation. DE drafted the manuscript with input from all authors. All authors have a substantial contribution in revising and finalizing the manuscript. All authors read and approved the final version of the manuscript.

\section{Acknowledgements}

We would like to thank the DHS program, for providing the dataset used in this study. 


\section{Abbreviations}

AOR: adjusted odds ratio; Cl: confidence intervals; EMDHS: Ethiopian mini demographic health survey; GIS: geographic information system; HAZ: height-for-age; ICC: intra-cluster correlation; MOR: median odds ratio; PCV: proportional change in variance; SD: standard deviation; WHO: world health organization.

\section{References}

1. WHO. Stunting in a nutshell [Internet]; 2015. Podcast. Available from:

https://www.who.int/news/item/19-11-2015-stunting-in-a-nutshell.

2. Victora CG, Adair L, Fall C, Hallal PC, Martorell R, Richter L, Sachdev HS, Maternal and Child Undernutrition Study Group. Maternal and child undernutrition: consequences for adult health and human capital. Lancet. 2008;371(9609):340-57.

3. Black RE, Allen LH, Bhutta ZA, Caulfield LE, deOnis M, Ezzati M, et al. Maternal and child undernutrition: global and regional exposures and health consequences. Lancet. 2008;371:243-60.

4. Gluckman PD, Hanson MA, Beedle AS. Early life events and their consequences for later disease: a life history and evolutionary perspective. Am J Hum Biol. 2007;19:1-19.

5. Uauy R, Kain J, Mericq V, Rojas J, Corvalan C. Nutrition, child growth, and chronic disease prevention. Ann Med. 2008;40:11-20.

6. Black RE, Victora CG, Walker SP, Bhutta ZA, Christian P, de Onis M, et al. Maternal and child undernutrition and overweight in low-income and middle-income countries. Lancet. 2013;382:427-51.

7. UNICEF W, World bank, . Levels and trends in child malnutrition. Geneve; 2019.

8. Ethiopian Public Health Institute (EPHI) [Ethiopia] and ICF. 2021. Ethiopia Mini Demographic and Health Survey 2019: Final Report. Rockville, Maryland, USA: EPHI and ICF.

9. Sisay FT, Sh Z, Lema M, Wubarege S. Prevalence and associated factors of stunting among 6-59 months children in pastoral Community of Korahay Zone, Somali regional state, Ethiopia. J Nutr Disord Ther. 2017. .

10. Amare D, Negassie A, Tsegaye B, Assefa B, Ayenie B. Prevalence of undernutrition and its associated factors among children below five years of age in bure town, west Gojjam zone, Amhara National Regional State, Northwest Ethiopia. Adv Public Health. 2016.

11. Ma'alin A, Birhanu D, Melaku S, Tolossa D, Mohammed Y, Gebremicheal K. Magnitude and factors associated with malnutrition in children 6-59 months of age in Shinille Woreda, Ethiopian Somali regional state: a crosssectional study. BMC Nutrition. 2016;2(1):44. 
12. Fikadu T, Assegid S, Dube L. Factors associated with stunting among children of age 24 to 59 months in Meskan district, Gurage zone, South Ethiopia: a case-control study. BMC Public Health. 2014;14(1):800.

13. Tamiru MW, Tolessa BE, Abera SF. Under nutrition and associated factors among under-five age children of Kunama ethnic groups in Tahtay Adiyabo Woreda. Tigray regional state, Ethiopia: community based study. Int J Nutr Food Sci. 2015;4(3):277-88.

14. Asfaw $M$, Wondaferash $M$, Taha $M$, Dube L. Prevalence of undernutrition and associated factors among children aged between six to fifty nine months in Bule Hora district, South Ethiopia. BMC Public Health. 2015;15(1):41.

15. Esri, ArcGIS®Desktop 10.7: ArcMap ${ }^{\mathrm{TM}}$ Functionality Matrix. 2019, Esri: USA.

16. Demlie YW, Yenit MK, Akalu TY. Geographical inequalities and determinants of stunting among under-five children in Ethiopia, 2016 EDHS, General Estimating Equation Model. 2020.

17. Hailu BA, Bogale GG, Beyene JJSr. Spatial heterogeneity and factors influencing stunting and severe stunting among under-5 children in Ethiopia: spatial and multilevel analysis. 2020;10(1):1-10.

18. Alemu ZA, Ahmed AA, Yalew AW, Birhanu BS. Non random distribution of child undernutrition in Ethiopia: spatial analysis from the 2011 Ethiopia demographic and health survey. International Journal for Equity in Health. 2016;15(1):198.

19. Adekanmbi VT, Uthman OA, Mudasiru OM. Exploring variations in childhood stunting in Nigeria using league table, control chart and spatial analysis. BMC Public Health. 2013;13:361.

20. Khamis FG, El-Refae GA. Association between Spatial Patterns of Acute Malnutrition and Household Income in Iraq-2004. Int J Statistics Probability. 2012;1(1):43-52.

21. Haile D, Azage M, Mola T, Rainey R. Exploring spatial variations and factors associated with childhood stunting in Ethiopia: spatial and multilevel analysis. BMC Pediatrics. 2016;16(1):49.

22. Kamal S. Socio-economic determinants of severe and moderate stunting among under-five children of rural Bangladesh. Mal J Nutr. 2011;17(1):105-18.

23. Rakotomanana H, Gates GE, Hildebrand D, Stoecker BJ. Determinants of stunting in children under 5 years in Madagascar. Matern Child Nutr. 2016: e12409. https://doi.org/10.1111/mcn.12409.

24. Ntenda PAM, Chuang Y-C. Analysis of individual-level and community-level effects on childhood undernutrition in Malawi. Pediatr Neonatol. 2017;59: 380-9.

25. Dasgupta A, Parthasarathi R, Biswas R, Geethanjali A. Assessment of under nutrition with composite index of anthropometric failure (CIAF) among under-five children in a rural area of West 
Bengal. Indian J Community Health. 2014;26(2):132-8.

26. Khan REA, Raza MA. Determinants of malnutrition in Indian children: new evidence from IDHS through CIAF. Qual Quant. 2016;50(1):299-316.

27. Wamani H, Åstrøm AN, Peterson S, Tumwine JK, Tylleskär T. Boys are more stunted than girls in sub-Saharan Africa: a meta-analysis of 16 demographic and health surveys. BMC Pediatr. 2007;7(1):17.

28. García Cruz LM, González Azpeitia G, Reyes Súarez D, Santana Rodríguez A, Loro Ferrer JF, SerraMajem L. Factors associated with stunting among children aged 0 to 59 months from the central region of Mozambique. Nutrients. 2017;9(491):1-16. https://doi.org/10.3390/nu9050491.

29. Bukusuba J, Kaaya A, Atukwase A. Predictors of Stunting in Children Aged 6 to 59 Months: A CaseControl Study in Southwest Uganda. Food Nutr Bull. 2017. https://doi.org/10.1177/0379572117731666.

30. Condo JU, Gage A, Mock N, Rice J, Greiner T. Sex differences in nutritional status of HIV-exposed children in Rwanda: a longitudinal study. Trop Med Int Health. 2015;20(1):17-23.

31. Olack B, Burke H, Cosmas L, Bamrah S, Dooling K, Feikin DR, et al. Nutritional status of under-five children living in an informal urban settlement in Nairobi, Kenya. J Health Popul Nutr. 2011;29(4):357.

32. Kabubo-Mariara J, Ndenge GK, Mwabu DK. Determinants of children's nutritional status in Kenya: evidence from demographic and health surveys. J African Economies. 2009;18:363-87.

33. Adekanmbi VT, Kayode GA, Uthman OA. Individual and contextual factors associated with childhood stunting in Nigeria: a multilevel analysis. Matern Child Nutr. 2013;9(2):244-59.

34. Keino S, Plasqui G, Ettyang G, van den Borne B. Determinants of stunting and overweight among young children and adolescents in sub-Saharan Africa. Food Nutr Bull. 2014;35(2):167-78.

35. Semba RD, de Pee S, Sun K, Sari M, Akhter N, Bloem MW. Effect of parental formal education on risk of child stunting in Indonesia and Bangladesh: a cross-sectional study. Lancet. 2008;371(9609):3228.

36. Makoka D. The Impact of Maternal Education on Child Nutrition: Evidence from Malawi, Tanzania, and Zimbabwe. DHS working Papers. 2013;84.

37. Urke HB, Bull T, Mittelmark MB. Socioeconomic status and chronic child malnutrition: Wealth and maternal education matter more in the Peruvian Andes than nationally. Nutrition Res. 2011;31(10):741-7.

38. Tessema F, Asefa M, Ayele F. Mothers' Health Services Utilization and Health Care Seeking Behavior During Infant Rearing: A Longitudinal Community Based Study, South West Ethiopia. Ethiopian J Health Development. 2002;16:51-8. 
39. Assefa T, Belachew T, Ayalew T, Deribew A. Mothers' Health Care Seeking Behavior For Childhood Illnesses In Derra District, Northshoa Zone, Oromia Regional State, Ethiopia. Ethiopian J Health Development. 2008;18(3):90-3.

40. Hong R, Banta JE, Betancourt JA. Relationship between household wealth inequality and chronic childhood under-nutrition in Bangladesh. Int J Equity Health. 2006;5:15.

41. Hong R, Mishra V. Effect of wealth inequality on chronic under-nutrition in Cambodian children. J Health Popul Nutr. 2006;24(1):89-99.

42. Hong R. Effect of economic inequality on chronic childhood undernutrition in Ghana. Public Health Nutr. 2007;10(4):371-8.

43. Taruvinga A, Muchenje V, Mushunje A: Determinants of rural household dietary diversity: The case of Amatole and Nyandeni districts, South Africa. International Journal of Development and Sustainability. 2013;2(4):1-15.

44. Doan D. Does income growth improve diet diversity in China?Selected Paper prepared for presentation at the 58 the AARES Annual Conference, Port Macquarie, New South Wales. 2014.

45. Gribble JN, Murray NJ, Menott EP. Reconsidering childhood undernutrition: can birth spacing make a difference? An analysis of the 2002-2003 El Salvador National Family Health Survey. Matern Child Nutr. 2008;5(1):49-63.

46. Ikeda N, Irie Y, Shibuya K. Determinants of reduced child stunting in Cambodia: analysis of pooled data from three Demographic and Health Surveys. Bull World Health Organ. 2013;91:341-9.

47. Dewey KG, Cohen RJ. Does birth spacing affect maternal or child nutritional status? A systematic literature review. Maternal Child Nutrition. 2007;3:151-73.

48. Kandala N-B, Madungu TP, Emina JB, Nzita KP, Cappuccio FP. Malnutrition among children under the age of five in the Democratic Republic of Congo (DRC): does geographic location matter? BMC Public Health. 2011;11(1):261.

49. Teshome B, Kogi-Makau W, Getahun Z, Taye G. Magnitude and determinants of stunting in children underfive years of age in food surplus region of Ethiopia: the case of west gojam zone. Ethiop $\mathrm{J}$ Health Dev. 2009; 23(2):99-106.

\section{Tables}

Table 1 Socio-demographic characteristics of children under age 5 in Ethiopia, EMDHS 2019 


\begin{tabular}{|c|c|c|c|}
\hline Variables & Total n (\%) & Stunted n (\%) & Normal n (\%) \\
\hline \multicolumn{4}{|c|}{ Age of a child (months) } \\
\hline $6-11$ & $1,000(20.12)$ & $221(22.1)$ & 779 (77.9) \\
\hline $12-23$ & $1,005(20.22)$ & $327(32.64)$ & $677(67.36)$ \\
\hline $24-35$ & $979(19.70)$ & $445(45.45)$ & $534(54.54)$ \\
\hline $36-47$ & $1,042(20.95)$ & $427(41.02)$ & $614(58.98)$ \\
\hline $48-59$ & $945(19.05)$ & $411(43.49)$ & $534(43.49)$ \\
\hline \multicolumn{4}{|l|}{ Child sex } \\
\hline Female & $2,441(49.11)$ & $819(35.55)$ & $1,622(66.45)$ \\
\hline Male & $2,530(50.89)$ & $1,013(40.04)$ & $1,517(59.96)$ \\
\hline \multicolumn{4}{|l|}{ Birth interval } \\
\hline$<24$ months & $811(16.33)$ & $346(42.66)$ & $465(57.34)$ \\
\hline$>=24$ months & $4,160(83.67)$ & $1,487(35.75)$ & $2,673(64.25)$ \\
\hline \multicolumn{4}{|l|}{ Type of birth } \\
\hline Single & $4,863(97.83)$ & $1,770(36.39)$ & $3,093(63.61)$ \\
\hline Multiple & $108(2.17)$ & $62(57.41)$ & $46(42.59)$ \\
\hline \multicolumn{4}{|c|}{ Maternal education } \\
\hline No education & $2,665(53.60)$ & $1,111(41.68)$ & $1,154(58.32)$ \\
\hline Primary & 1,759 (35.39) & $621(35.30)$ & $1,138(64.70)$ \\
\hline Secondary & $366(7.37)$ & $70(19.13)$ & $296(80.87)$ \\
\hline Higher & $181(3.65)$ & $31(17.13)$ & $150(82.87)$ \\
\hline \multicolumn{4}{|l|}{ Wealth index } \\
\hline Poorest & $1,140(22.97)$ & $486(42.63)$ & $654(57.37)$ \\
\hline Poorer & $1,098(22.09)$ & $426(38.79)$ & $672(61.21)$ \\
\hline Middle & $933(18.78)$ & $395(42.34)$ & $538(57.66)$ \\
\hline Richer & $880(17.72)$ & $317(36.02)$ & $563(63.98)$ \\
\hline Richest & $917(18.46)$ & 207 (22.57) & 710 (77.43) \\
\hline \multicolumn{4}{|l|}{ Residence } \\
\hline Urban & $1,249(25.12)$ & $320(25.62)$ & $929(74.38)$ \\
\hline Rural & $3,722(74.88)$ & $1,512(40.62)$ & $2,210(59.38)$ \\
\hline
\end{tabular}




$\begin{array}{|llll|}\text { Region } & & & \\ \text { Tigray } & 351(7.06) & 172(49.00) & 179(51.00) \\ \text { Afar } & 74(1.50) & 32(43.24) & 42(56.76) \\ \text { Oromiara } & 957(19.25) & 391(40.86) & 566(59.14) \\ \text { Somali } & 1,978(39.70) & 707(35.74) & 1,271(64.26) \\ \text { b/gumz } & 343(6.91) & 105(30.61) & 238(69.39) \\ \text { SNNPR } & 58(1.18) & 24(41.38) & 34(58.62) \\ \text { Gambela } & 1,007(20.27) & 366(36.35) & 641(63.65) \\ \text { Harari } & 21(0.43) & 4(19.05 & 17(80.95) \\ \text { Addis ababa } & 14(0.29) & 5(35.71) & 9(64.29) \\ \text { Dire dawa } & 138(2.78) & 19(13.77) & 119(86.23) \\ \end{array}$

Table 2 Random effect and model fitness showing the influence of community characteristics on childhood stunting in Ethiopia, EMDHS 2019

\begin{tabular}{|lllll|}
\hline Parameter & Model $1^{\mathrm{a}}$ & Model $2^{\mathrm{b}}$ & ${\text { Model } 3^{\mathrm{c}}}$ & Model $^{\mathrm{d}}$ \\
\hline Random effects & & & & \\
Variance (SE) & $0.436(0.068)^{*}$ & $0.326(0.058)^{*}$ & $0.191(0.042)^{*}$ & $0.166(0.041)^{*}$ \\
PCV (\%) & Reference & 25.2 & 56.2 & 61.9 \\
ICC (\%) & 11.7 & 9.1 & 5.5 & 4.8 \\
MOR & 1.88 & 1.72 & 1.52 & 1.47 \\
Model fit statistics & & & & 6,042 \\
DIC(-2log likelihood) & 6,462 & 6,130 & 6,330 & \\
\hline
\end{tabular}

SE Standard Error, PCV Proportional Change in Variance, ICC Intra-class Correlation Coefficient, MOR Median Odds Ratio, DIC Deviation Information Criteria

${ }^{\text {a } M o d e l} 1$ is an empty model, a baseline model without any explanatory variable

${ }^{\text {b }}$ Model 2 is adjusted for individual-level factors

${ }^{c}$ Model 2 is adjusted for community-level factors 
${ }^{\mathrm{d}}$ Model 2 is adjusted for individual and community-level factors

${ }^{*}$ P-value $<0.001$

Table 3 Multivariable multilevel logistic regression analysis of factors associated with childhood stunting in Ethiopia, EMDHS 2019 


\begin{tabular}{|c|c|c|c|}
\hline \multirow[t]{2}{*}{ Variables } & Model 2 & Model 2 & Model 2 \\
\hline & AOR $(95 \% \mathrm{Cl})$ & AOR $(95 \% \mathrm{Cl})$ & AOR $(95 \% \mathrm{Cl})$ \\
\hline \multicolumn{4}{|c|}{ Individual-level factors } \\
\hline \multicolumn{4}{|c|}{ Age of a child (months) } \\
\hline $6-11$ & 1.00 & & 1.00 \\
\hline $12-23$ & $2.37(1.91-2.94)$ & & $2.36(1.90-2.92)^{\star \star \star}$ \\
\hline $24-35$ & $3.75(3.04-4.62)$ & & \multirow{3}{*}{$\begin{array}{l}3.74(3.04-4.59)^{\star \star \star} \\
3.05(2.47-3.76)^{\star \star \star} \\
2.78(2.26-3.43)^{\star \star \star}\end{array}$} \\
\hline $36-47$ & $3.07(2.49-3.79)$ & & \\
\hline $48-59$ & $2.79(2.27-3.44)$ & & \\
\hline \multicolumn{4}{|l|}{ Child sex } \\
\hline Female & 1.00 & & 1.00 \\
\hline Male & $1.19(1.05-1.35)$ & & $1.21(1.06-1.37)^{\star \star}$ \\
\hline \multicolumn{4}{|l|}{ Birth interval } \\
\hline$>=24$ months & 1.00 & & 1.00 \\
\hline$<24$ months & $1.25(1.06-1.48)$ & & $1.30(1.11-1.53)^{\star *}$ \\
\hline \multicolumn{4}{|l|}{ Type of birth } \\
\hline Single & 1.00 & & 1.00 \\
\hline Multiple & $2.45(1.61-3.73)$ & & $2.46(1.62-3.74)^{\star \star *}$ \\
\hline \multicolumn{4}{|c|}{ Maternal education } \\
\hline No education & 1.00 & & 1.00 \\
\hline Primary & $0.98(0.85-1.14)$ & & $1.00(0.86-1.18)$ \\
\hline Secondary & $0.60(0.45-0.80)$ & & $0.63(0.47-0.84)^{\star \star}$ \\
\hline Higher & $0.52(0.35-0.77)$ & & $0.55(0.38-0.82)^{* *}$ \\
\hline \multicolumn{4}{|l|}{ Wealth index } \\
\hline Richest & 1.00 & & 1.00 \\
\hline Richer & $1.91(1.48-2.47)$ & & $1.75(1.29-2.36)^{\star \star \star}$ \\
\hline Middle & $2.27(1.75-2.95)$ & & $2.01(1.46-2.76)^{\star \star \star}$ \\
\hline Poorer & $1.98(1.52-2.56)$ & & $1.84(1.34-2.52)^{\star \star \star}$ \\
\hline
\end{tabular}




\begin{tabular}{|lll|} 
Poorest & $2.08(1.62-2.67)$ & $2.00(1.46-2.73)^{\star \star \star}$ \\
Community-level factors & & \\
Residence & & \\
Urban & 1.00 & 1.00 \\
\hline Region & $1.78(1.42-2.22)$ & $1.07(0.81-1.40)$ \\
Addis ababa & & \\
Tigray & 1.00 & 1.00 \\
Afar & $4.08(2.43-6.79)$ & $3.64(2.17-6.11)^{\star \star \star}$ \\
Amhara & $3.01(1.82-4.99)$ & $2.02(1.19-3.39)^{\star \star}$ \\
Oromia & $2.88(1.73-4.78)$ & $2.29(1.37-3.86)^{\star \star}$ \\
Somali & $2.18(1.33-3.59)$ & $1.58(0.95-2.64)$ \\
Benishangul Gumz & $1.69(1.02-2.84)$ & $1.02(0.60-1.74)$ \\
SNNPR & $2.58(1.54-4.34)$ & $1.87(1.10-3.17)^{\star}$ \\
Gambela & $2.25(1.36-3.72)$ & $1.62(0.97-2.72)$ \\
Harari & $0.90(0.53-1.16)$ & $0.69(0.39-1.20)$ \\
Dire dawa & $2.16(1.29-3.59)$ & $1.95(1.17-3.25)^{\star}$ \\
\hline
\end{tabular}

AOR adjusted odds ratio, $\mathrm{Cl}$ confidence interval, $1.00=$ reference ${ }^{*} \mathrm{P}<0.05,{ }^{* \star} \mathrm{P}<0.01{ }^{\star \star \star} \mathrm{P}<0.001$

\section{Figures}




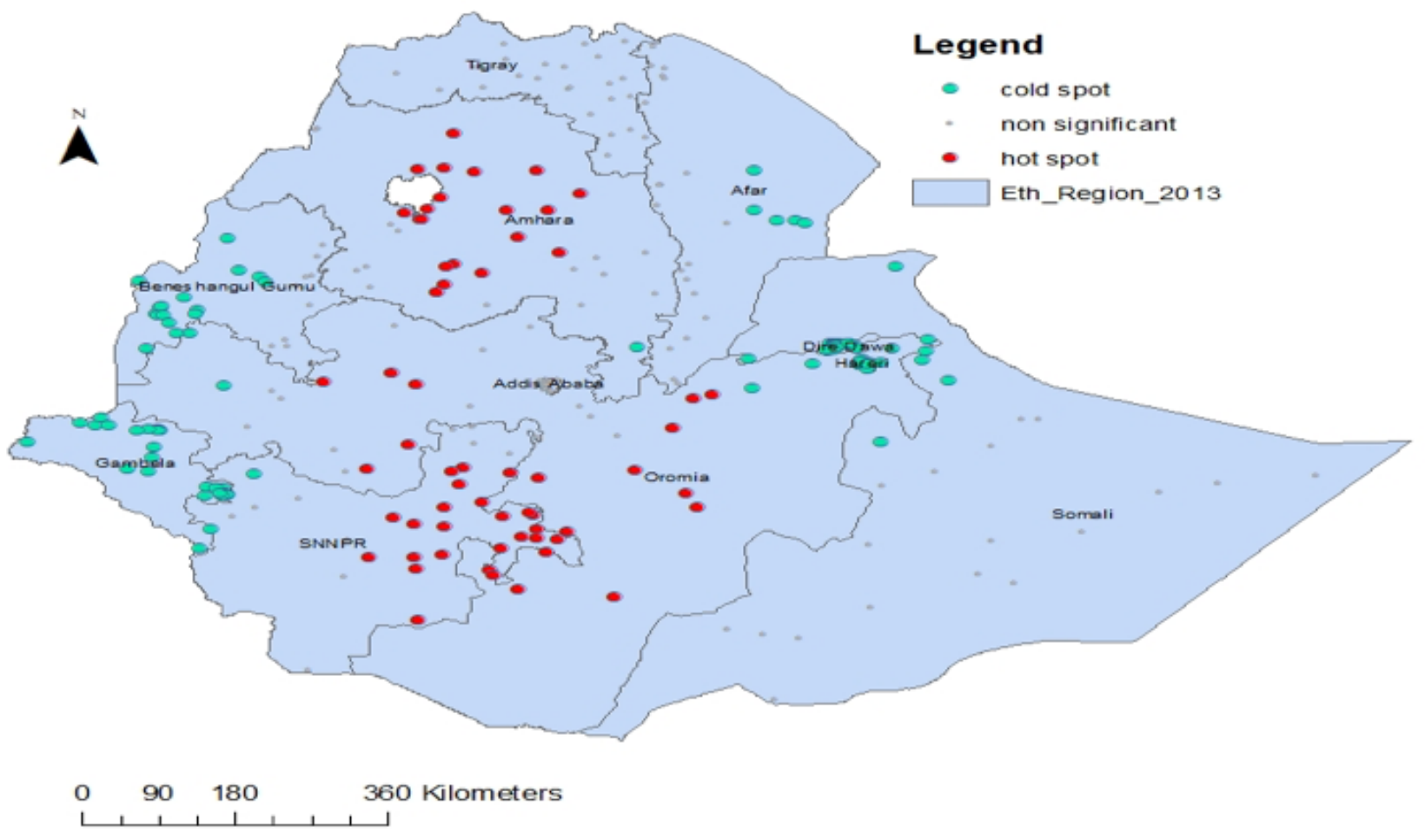

Figure 1

Spatial distributions of stunting in Ethiopia, EMDHS 2019 


\section{Legend}

- case

\section{CLUSTER}

$\hat{A}$

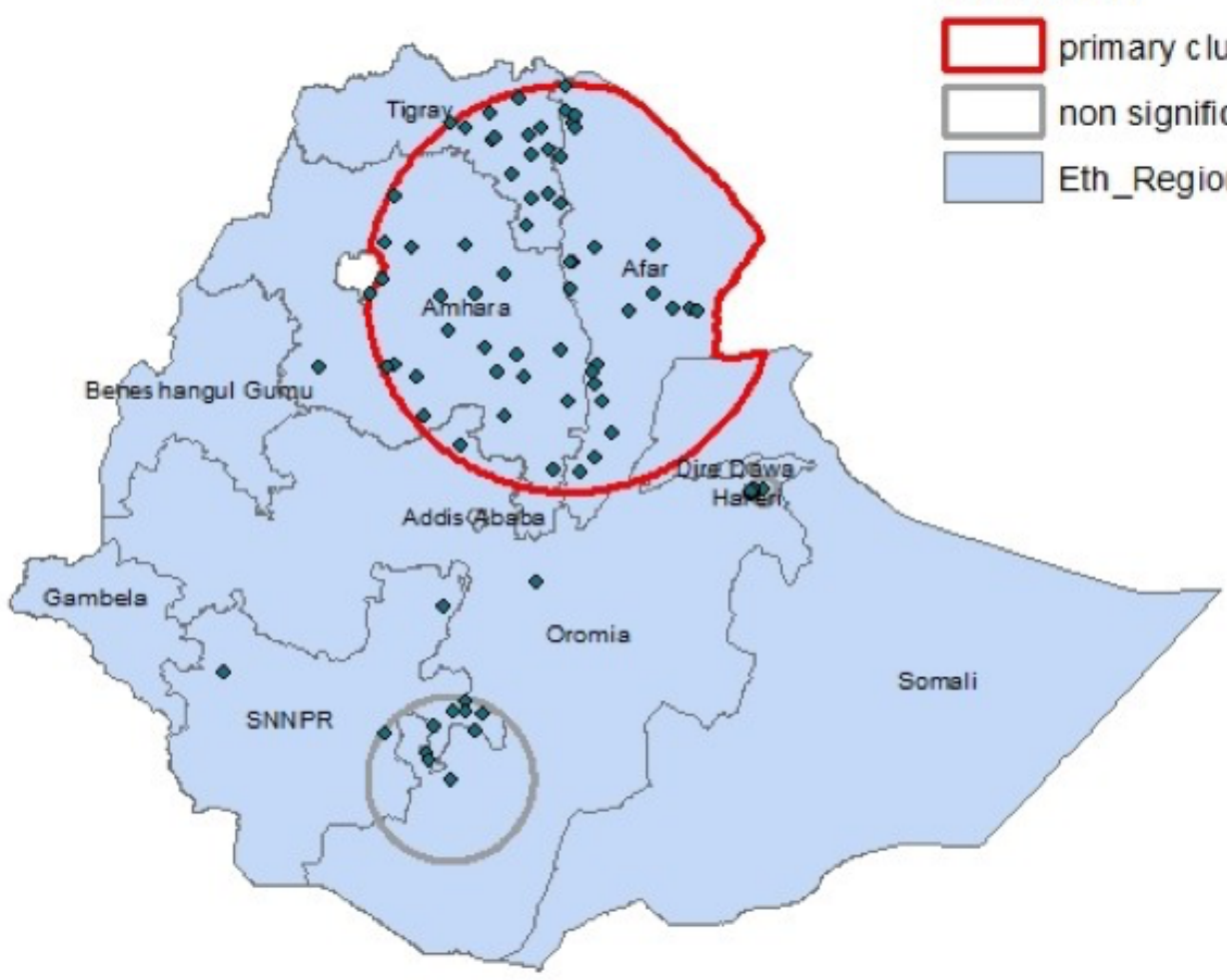

\begin{tabular}{llll}
0 & $135 \quad 270 \quad 540$ Kilometers \\
\hline
\end{tabular}

\section{Figure 2}

Sat scan analysis of childhood stunting in Ethiopia, EMDHS 2019 